\title{
Vitamin D and IL28B Genotyping as Predictors for Antiviral Therapy: A Retrospective Study in Egyptian HCV Genotype 4a
}

\author{
Nadia Abdelaaty Abdelkader ${ }^{1}$, Soha Saoud Abdelmoniem ${ }^{2}$, Dina Sabry ${ }^{3 *}$, Amin \\ Mohamad Abdelbaky ${ }^{4}$, Maram M Mahdy ${ }^{5}$, Eman Zaky ${ }^{5}$ and Wessam Elsayed \\ Saad $^{6}$ \\ ${ }^{1}$ Tropical Medicine Department, Ain Shams University, Cairo, ${ }^{2}$ Tropical Medicine \& Gastroenterology Department, Assiut \\ University, Assiut, ${ }^{3}$ Medical Biochemistry and Molecular Biology Department, Cairo University, ${ }^{4}$ Tropical Medicine Department, \\ National Hepatology and Tropical Medicine Research Institute (NHTMRI), 5Internal Medicine Department, Ain Shams \\ University, ${ }^{6}$ Clinical Pathology Deparment, Ain Shams University, Cairo, Egypt
}

*For correspondence: Email: dinasabry@kasralainy.edu.eg, dinnasabry69@yahoo.com

\begin{abstract}
Purpose: To evaluate the role of pre-treatment vitamin D serum level and interleukin28B (IL28B) (rs 12979860) polymorphism in chronic hepatitis $C$ (CHC) genotype 4a patients treated with pegylated interferon a2-A and ribavirin (peg IFN+RBV) as predictors of response.

Methods: A retrospective study of clinical and pathological data and stored blood samples of 150 naïve chronic hepatitis $\mathrm{C}(\mathrm{CHC})$ genotype $4 a$ patients, treated with pegylated interferon and ribavirin for 48 weeks. Follow-up to detect sustained virological response (SVR) was carried out. Based on SVR, two groups were studied; group 1 consisted of 75 responder patients to pegylated IFN + RBV therapy while group 2 comprised of 75 non-responder patients to standard hepatitis C virus (HCV) therapy. Vitamin D serum levels were assessed using Enzyme Linked Immunoassay (ELISA), quantitative reverse transcriptase- polymerase chain reaction (qRT-PCR for HCV RNA ), and IL28B gene polymorphism by Restriction Fragment Length Polymorphism Polymerase Cchain Reaction (RFLP-PCR).

Results: Pretreatment vitamin $D$ level was significantly higher in group 1 than in group $2(p<0.001)$. The sensitivity and specificity of vitamin $D$ level for prediction of SVR at a cutoff value of $29.75 \mathrm{ng} / \mathrm{ml}$ were 100 and $96 \%$, respectively, with area under the curve (AUC) of $0.995(p<0.001)$. A significant difference was detected between baseline vitamin $D$ level for early versus advanced fibrosis stage $(p=$ 0.01) in group 1.

Conclusion: Pretreatment vitamin D serum level (at a cutoff value of $29.75 \mathrm{ng} / \mathrm{ml}$ ), IL28B gene polymorphism and quantitative HCV RNA are independent trait predictors of SVR.
\end{abstract}

Keywords: Vitamin D, Interleukin 28B, Chronic hepatitis C, Sustained virological response (SVR), Antiviral, Genotyping

Tropical Journal of Pharmaceutical Research is indexed by Science Citation Index (SciSearch), Scopus, International Pharmaceutical Abstract, Chemical Abstracts, Embase, Index Copernicus, EBSCO, African Index Medicus, JournalSeek, Journal Citation Reports/Science Edition, Directory of Open Access Journals (DOAJ), African Journal Online, Bioline International, Open-J-Gate and Pharmacy Abstracts

\section{INTRODUCTION}

The combination of pegylated interferon alpha-2a or alpha-2b plus ribavirin for 48 weeks is the recommended treatment for patients with $\mathrm{HCV}$ genotype 4, but many patients will not respond satisfactorily to this therapy [1]. It also has side effects that prevent some patients from completing therapy [2]. For these reasons, identification of the determinants of 
responsiveness to treatment is a matter of high priority.

Genome-wide association studies have recently revealed that single nucleotide polymorphisms (SNPs) within or adjacent to IL28B (19q13) that codes for interferon- $\lambda 3$, predict spontaneous resolution of $\mathrm{HCV}$. It was found that IL28B rs12979860 is strongly associated with the chance to clear HCV spontaneously in populations of African or European ancestry, with an approximately three times higher clearance rate in individuals with the rs12979860 genotype $\mathrm{C} / \mathrm{C}$ versus $\mathrm{C} / \mathrm{T}$ and $\mathrm{T} / \mathrm{T}$ [3]. Nevertheless, it was estimated that IL28B variations account for about $15 \%$ of the inter-individual variability of sustained virological response (SVR), thus supporting the necessity for additional predictor(s) of the response to treatment. Recent predictors include vitamin D deficiency [4,5]. Therefore, biological models for the prediction of SVR should include a variety of parameters besides IL28B genotyping, as this would offer better accuracy compared with IL28B typing alone [5].

Vitamin $D$ is considered a critical regulator of immunity, playing a role in both innate and cellmediated immune responses [6]. Vitamin D suppresses production of T-helper (TH)-1 lymphocyte type cytokines, such as interferon $\lambda$ (IFN $\lambda$ ) and IL-2, and consequently leads to enhanced production of $\mathrm{TH} 2$ cytokines like IL-4 and IL-5 that promote humoral immune responses. The vitamin also enhances innate immunity by directly inducing gene expression of anti-microbial peptides, such as cathelicidin and b-defensin-2, in various cell types. Its deficiency is associated with several immune-mediated diseases and increased susceptibility to infection and cancer [7]. Interestingly, a significant progressive decline in active vitamin $D$ levels is associated with progressive exacerbation of the hepatic disease states. The above results indicate that a decrease in vitamin $D$ levels could reflect the severity of hepatocellular injury and so serve as a new hepatic biomarker in progressive liver diseases $[8,9]$.

Recently, vitamin D insufficiency (defined as 25hydroxy-vitamin D serum level of $20-29 \mathrm{ng} / \mathrm{mL}$ ) has been proposed as a predictor of failure of treatment of chronic hepatitis C with PEG-IFNa$2 a$ and ribavirin [10]. Moreover, severe vitamin D deficiency is a common feature of chronic hepatitis $\mathrm{C}$, even in the absence of advanced liver fibrosis [11]. On the other hand, it was reported that baseline $25(\mathrm{OH}) \mathrm{D}$ level is not independently associated with SVR or fibrosis stage in hepatitis $C$ virus genotype-1(HCV-1), but vitamin $D$ deficiency is associated with high activity grade [12].

This study aims to evaluate the role of Pretreatment vitamin D serum level and IL-28B (rs12979860) polymorphism among other predictors of SVR and to study the relation between vitamin $D$ serum level and hepatic fibrosis/activity scoring.

\section{EXPERIMENTAL}

\section{Patients}

This is a retrospective study of collected clinical data and laboratory work assessment for 150 stored blood samples of naïve, chronic hepatitis C (CHC) patients who were eligible for the standard care of therapy. The above data were obtained from the Hepatology Outpatient Clinic of National Hepatology and Tropical Medicine Research Institute (NHTMRI) and Hepatology Outpatient Clinic of Tropical Medicine department, Ain Shams university hospital, Cairo, Egypt. The sample size was estimated after literature review.

Following ethical approval (no. 8-2013) by the National Hepatology and Tropical Medicine Research Institute (NHTMRI), Cairo, Egypt, 150 patients were selected on the basis of elevated ALT level, presence of both HCV antibodies and RNA detected in the serum of all studied patients for at least 6 months. Chronic hepatitis was confirmed by histological observation of specimens obtained by true-cut needle biopsy (HS 16 G. Italy). Histological grades of chronic hepatitis was determined according to Metavir score where necroinflammation is classified into $(A 0=$ no inflammation; $A 1=$ mild inflammation; $\mathrm{A} 2=$ moderate inflammation; $\mathrm{A} 3=$ severe inflammation) and fibrosis is classified into (F0 = no fibrosis; $\mathrm{F} 1=$ portal tract expansion by fibrosis; F2= < $50 \%$ bridging fibrosis; F3 = > 50 $\%$ bridging fibrosis including incomplete cirrhosis; F4 = established cirrhosis) [13]. All patients included in this study had HCV genotype 4a.

None of the studied patient had obesity (BMI > 30), decompensated cirrhosis, autoimmune disorders, DM, renal dysfunction, concomitant HBV or HIV infection, cardiac insults, any malignancy or the concomitant use of drugs known to affect serum vitamin $D$ concentration.

All patients received pegylated interferon $\alpha-2 A$ (Pegasys $\AA 180 \mathrm{mcg}$ ) on a once weekly basis and ribavirin 1,000 (for those $\leq 75 \mathrm{~kg}$ body 
weight) or $1,200 \mathrm{mg}$ (> 75kg body weight)/ day according to body weight for 48 weeks. Six months after treatment, a sustained virologic response was assessed (SVR was defined as an undetectable serum HCV RNA level at 24 weeks after stopping antiviral therapy) and accordingly and the patients were divided into 2 equal groups of 75 patients each; group 1 was made up of patients who responded to pegylated IFN + RBV combined standard HCV therapy and achieved SVR (negative HCV viremia 6 months after stopping therapy) while group 2 were those who did not respond to standard HCV therapy and they did not achieve SVR.

\section{Vitamin D serum level assessment}

Vitamin $D$ serum level was detected by ELISA 25-OH Vitamin D kit according to instructions of manufactures (DRG, international Inc., USA). The data are expressed as $\mathrm{ng} / \mathrm{ml}$ and normal 25$\mathrm{OH}$ vitamin $\mathrm{D}$ serum levels was defined as $>20$ $\mathrm{ng} / \mathrm{mL}$.

\section{DNA extraction and IL28B gene detection}

Whole blood DNA was extracted from $200 \mu \mathrm{l}$ blood with the QIAamp® DNA Blood Mini Kit (Qiagen, Hilden, Germany) according to the manufacturer's instructions. DNA quality and quantity was assessed by calculating the absorbance ratio OD260 $\mathrm{nm} / 280 \mathrm{~nm}$ using double beam UV spectrophotometer (Beckman, USA). IL28B rs12979860 genotyping was detected by RFLP-PCR method [14]. A 139 base pair (bp) product was obtained with the forward primer 5`- CCAGGGCCCCTAACCTCT $\neg G C A ~-~ 3 `$ and the reverse primer 5'GGGAGCGCGGAGT $\neg$ GCAATTCA - 3`using EzWayTM Direct Taq PCR Master mix kit (Koma Biotech Inc., Seoul, Korea) in $20 \mu \mathrm{L}$ reaction volume.

\section{qRT-PCR of HCV RNA}

This was done according to [15] using the AgPath-IDTM One -Step RT-PCR kit (Cat \# AM 1005) from Applied Biosystems (Foster City, CA, USA).

\section{Statistical analysis}

Patients' data were analyzed using SPSS 17.0 for Windows 7. Quantitative variables were expressed as mean and SD (standard deviation) and the qualitative variables were expressed by numbers (frequency) and percentage (male/female frequency, liver biopsy results and IL28B polymorphism. Data were compared using unpaired t-student test, Chi-square test, as appropriate. Logistic regression analysis with a forward approach was performed to identify independent predictors of SVR. ROC (receiver operating curve) was constructed and AUC (area under curve) was calculated. Optimal cut-off was determined for the variables required. $P<0.05$ was considered significant.

\section{RESULTS}

The studied groups included group 1: 75 responder patients to pegylated IFN + RBV combined therapy HCV standard therapy (32 males, $42.7 \%$ and 43 females, $57.3 \%$ ) while group 2: 75 non responders patients to $\mathrm{HCV}$ standard therapy (33 males, $44 \%$ and 42 females, $56 \%$ ). The baseline demographic, laboratory and histopathological characteristics of the studied population are reported in (Table 1).

\section{Vitamin D and HCV viral load assessments}

Pretreatment vitamin $D$ mean value was significantly higher $(65.09 \pm 17.4)$ in responders (group 1) compared to $15.48 \pm 7.48$ in non responders (group 2) $(p<0.01)$ (Table 1). Pretreatment HCV viral load by PCR mean value was significantly lower in responders compared to non responders $(p<0.01)$ (Table 1$)$. ROC for the sensitivity and specificity of baseline vitamin $\mathrm{D}$ level for prediction of SVR at a cut off value of $29.75 \mathrm{ng} / \mathrm{mL}$ were 100 and $96 \%$, respectively (area under the curve (AUC): 0.995 ( $p=0.001)$.

\section{Baseline vitamin D level and liver histopathology}

Inverse relation between mean baseline vitamin $\mathrm{D}$ and both activity grade and fibrosis stage was reported in both groups. However, it did not reach statistical significance in non-responders ( $p=0.42,0.9$ respectively) and regarding the activity grade in responders $(p=0.18)$. On the other hand, statistical significant difference was found between baseline mean vitamin $D$ serum value in early versus advanced fibrosis stage in responders $(p=0.01)$ (Table 2$)$.

\section{Predictors of response to standard care of therapy}

Univariate analysis revealed that SVR was influenced by ALT, IL28B gene polymorphism, vitamin $D$ serum level and $\mathrm{HCV}$ viral load (Table 3 ). Neither activity score nor fibrosis score was a significant predictor for response to therapy ( $p$ value $=0.826,0.783$ respectively) .

Trop J Pharm Res, October 2014; 13(10): 1727 
Table 1: Baseline demographic, laboratory and histopathological data for the studied groups

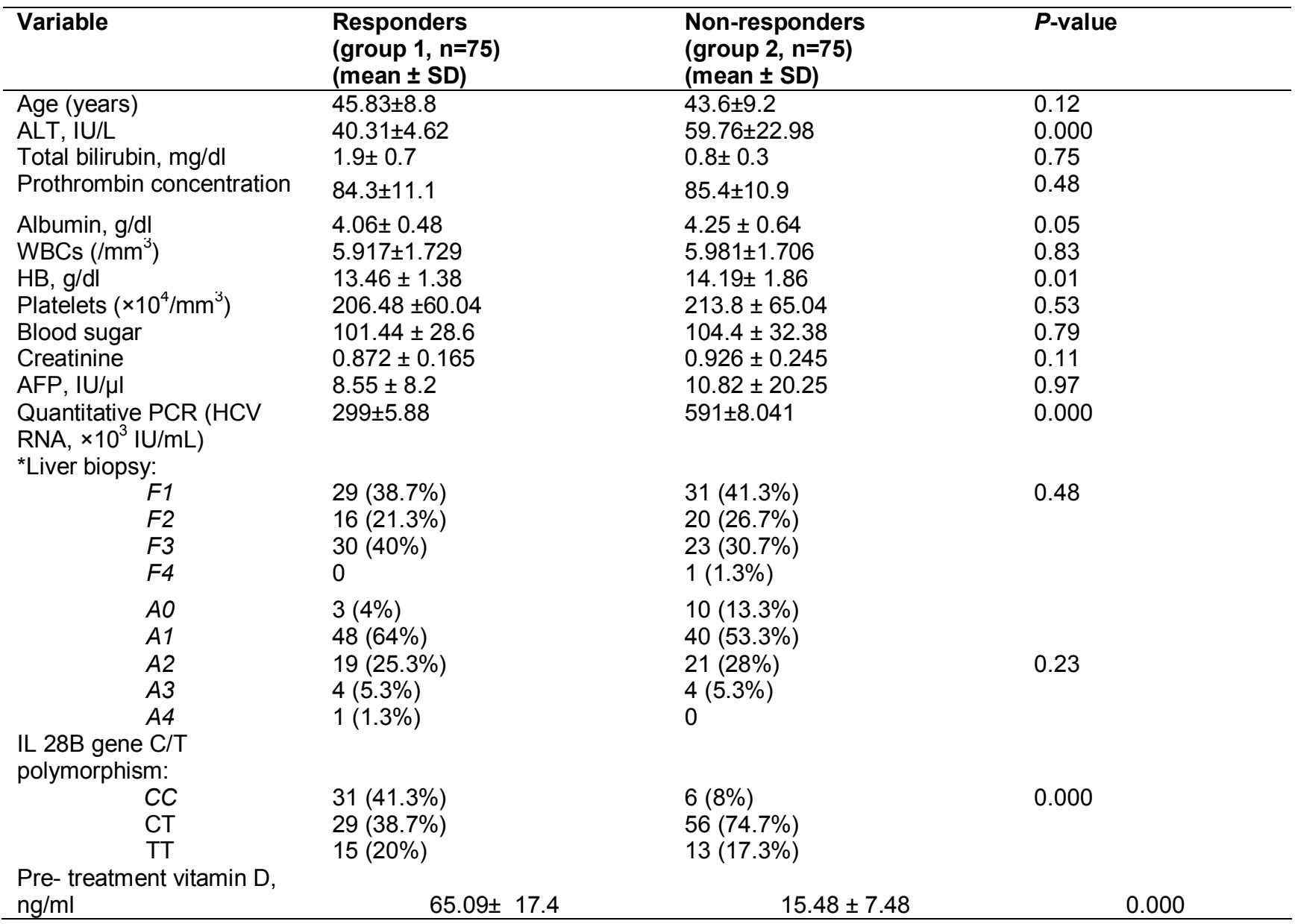

Abbreviations: $A L T$ - alanine aminotransferase. WBC - white blood cells. HB - heamoglobin. AFP - alphafeto protein. PCR - polymerase chain reaction. HCV - hepatitis C virus, IL-28B - interleukin-28B, * Liver biopsy; $F$ fibrosis score, $A$ - activity grade according to METAVIR

Table 2: Pretreatment vitamin $D$ mean serum level in different activity grades and fibrosis stages in studied groups

\begin{tabular}{lcccccc}
\hline & \multicolumn{2}{c}{ Responders } & $\boldsymbol{P}$ - & \multicolumn{2}{c}{ Non-responders } & $\boldsymbol{P}$ - \\
Variable & ${ }^{*} \boldsymbol{A} \mathbf{0}-\boldsymbol{A 2}$ & $\boldsymbol{A 3}-\boldsymbol{A 4}$ & value & $\boldsymbol{A} \mathbf{0}-\boldsymbol{A 2}$ & $\boldsymbol{A 3}-\boldsymbol{A 4}$ & value \\
Pretreatment & $76 \pm 19.42$ & $64.32 \pm 17.1$ & $\mathbf{0 . 1 8}$ & $48.67 \pm 35.3$ & $39.75 \pm 27.8$ & $\mathbf{0 . 4 2}$ \\
Vitamin $D$ & ${ }^{* *} \boldsymbol{F} \mathbf{1 - F 2}$ & $\boldsymbol{F 3}-\boldsymbol{F 4}$ & & $\boldsymbol{F 1}-\boldsymbol{F 2}$ & $\boldsymbol{F 3}-\boldsymbol{F 4}$ & \\
& $71.32 \pm 17.5$ & $60.94 \pm 16.3$ & $\mathbf{0 . 0 1}$ & $16.75 \pm 10.5$ & $14.89 \pm 5.6$ & $\mathbf{0 . 9}$ \\
\hline
\end{tabular}

${ }^{*} A$ : activity grade; A0-A2: early inflammation grades, A3-A4: advanced inflammation grades. ${ }^{* *} F$ : fibrosis stage; F1-F2: early fibrosis stages, F3-F4: advanced fibrosis stages

Table 3: Univariate analysis (with SVR as the dependent variable) and other items as independent variables) for predictors of SVR

\begin{tabular}{llll}
\hline Variable & OR & $\mathbf{9 5 \%} \mathbf{C l}$ & ${ }^{*} \boldsymbol{P}$-value \\
\hline ALT> 60 IU/ml & 0.904 & $0.86-0.94$ & 0.000 \\
IL28B polymorphism (CC vs. CT \& TT) & 4.67 & $2.32-9.39$ & 0.000 \\
Pretreatment & 1.279 & $1.152-1.421$ & 0.000 \\
Vitamin D >29.75 ng/ml & 1 & 1 & 0.025 \\
Pretreatment HCV RNA >600.000 IU/ml & 1 & 1 & \\
\hline
\end{tabular}

Chi-square test, Abbreviations: ALT - alanine aminotransferase; IL-28B - interleukin-28B; HCV - hepatitis $C$ virus; $\mathrm{Cl}$ - confidence interval; OR - odds ratio 
Table 4: Multivariate for predictors of SVR

\begin{tabular}{lccc}
\hline Variable & OR & 95\% Cl & P-value \\
\hline Pretreatment HCV viral load & 1.000 & - & 0.042 \\
( $>600.000$ IU/ml) & & & \\
IL28B (CC vs. CT\&TT) & 4.825 & $2.325-10.015$ & 0.000 \\
Pretreatment vitamin D $(>29.75 \mathrm{ng} / \mathrm{mL})$ & 0.767 & $0.612-0.961$ & 0.021 \\
\hline
\end{tabular}

OR: odds ratio, HCV: hepatitis C virus, IL-28B: interleukin-28B, Cl: confidence interval.
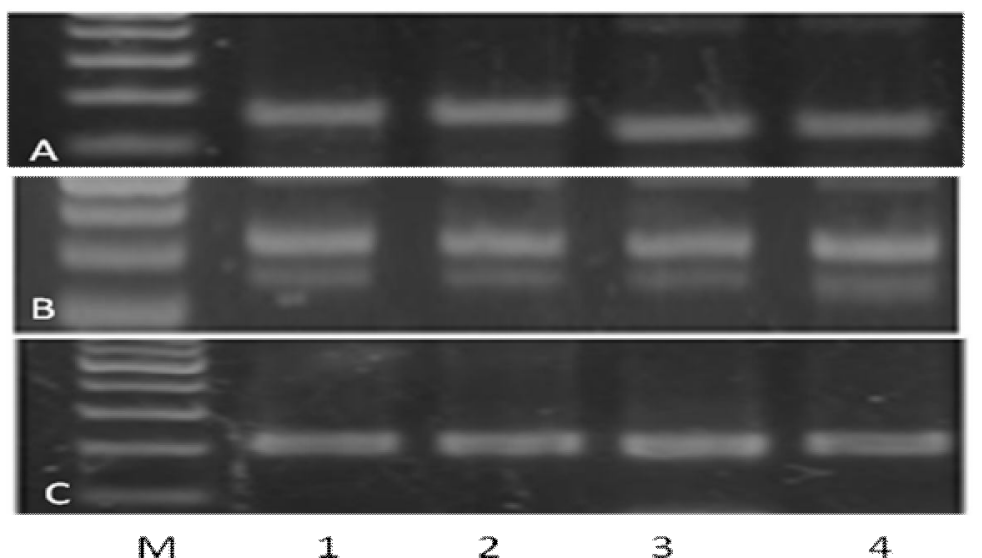

Figure 1: Agarose electrophoresis showng PCR products of il-28 gene polymorphism (A \& B) in HCV patients Lane M: DNA ladder marker; Lane 1 \& 2 (A): TT genotype of IL-28 polymorphism (139bp PCR product); Lane 2\&4 (A): CC genotype of IL-28 polymorphism (109bp PCR product); Lane 1-4 (B): CT genotype of IL-28 polymorphism (139+109bp PCR products); Lane 1-4 (C): GAPDH house keeping gene (internal control). Lane 1-4 (C): GAPDH house keeping gene (internal control)

On multivariate analysis revealed that vitamin $D$ level (> $29.75 \mathrm{ng} / \mathrm{ml}$ ) independent predictor of SVR (Table 4).

\section{Genotyping of IL28B and SVR}

IL-28B (rs 12978860) SNP among the studied groups was assessed by RFLP-PCR (Figure 1). The results of IL28B SNP (rs 12979860) genotyping in 150 chronic $\mathrm{HCV}$ patients as regard to their response to pegylated IFN + RBV combined therapy are represented in Table 1. A strong significant high increase in the incidence of the protective CC genotype in chronic $\mathrm{HCV}$ responder patients compared with the genotyping data of chronic $\mathrm{HCV}$ non responder patients was observed, $31 \% \mathrm{CC}$ in responder $\mathrm{CHC}$ vs. $6 \% \mathrm{CC}$ in non responder $\mathrm{CHC}$. Such a decline in the $\mathrm{CC}$ genotype was not associated with a comparable increase in the TT genotype; however a two fold increase $(74.7 \%$ vs. $38.7 \%)$ in the heterozygous genotype CT was observed in the responder $\mathrm{CHC}$ compared with the non responder $\mathrm{CHC}$.

\section{DISCUSSION}

This study showed that the pre-treatment vitamin $D$ mean value was significantly higher in patients who achieved SVR compared to those who did not and at a cut off value of $29.75 \mathrm{ng} / \mathrm{ml}$ it was 100 and $96 \%$ sensitive and specific respectively in predicting SVR. Moreover, an inverse relationship between baseline vitamin $D$ serum level and both activity grade and fibrosis stage of fibrosis was reported. IL-28B rs12979860 C/T polymorphism appeared to predict the rate of response to pegylated IFN + RBV combined therapy in $\mathrm{CHC}$ patients.

In our study and in agreement with [16], pretreatment vitamin D level assessment showed significantly higher mean value in patients who achieved SVR compared to those who did not. The supposed relationship between the rapid slope of the HCV RNA level after therapy initiation and vitamin $D$ suggests that the latter could amplify the immunological effect of IFN.

As many studies concerning the relevance of vitamin $D$ in the clinical setting have clearly shown that simple variations of vitamin $D$ serum levels above the limit of normality $(20 \mathrm{ng} / \mathrm{ml})$ seem to have a negligible biological effect the choice to analyze vitamin $D$ as a categorical variable appears to be appropriate. Therefore, results presented in this study showed that baseline vitamin $D$ level at a cut off value of $29.75 \mathrm{ng} / \mathrm{ml}$, comparable to that reported by [10], was 100 and $96 \%$ sensitive and specific respectively in predicting SVR. This study 
showed that all responder patients had pretreatment vitamin $D$ level above this cut off value compared to only 3 patients among non responder patients with statistical significant difference. Consequently, one might hypothesize that assessment of vitamin $D$ levels might be helpful as a strong predictor before starting antiviral therapy in patients with chronic hepatitis C.

We did not report any significant relation between baseline vitamin $D$ level with either age, pretreatment ALT, HCV RNA. However, an inverse relationship between baseline vitamin $D$ serum level and both activity grade and fibrosis stage of fibrosis was reported. In agreement with those previously published by Petta and coworkers [16] who reported an inverse association between vitamin $\mathrm{D}$ and both activity grading and fibrosis staging. However, this contradicts results by Bitetto et al [17] who reported a strong inverse association with fibrosis staging only. This could conceivably be related to the anti-inflammatory effects of vitamin $D$, given the contribution of inflammatory cell recruitment to hepatic fibrosis progression.

Furthermore, when we analyzed the predictive role of vitamin $\mathrm{D}$ as a categorical variable using a cutoff level of $29.75 \mathrm{ng} / \mathrm{ml}$ for both histology grading and fibrosis staging no significant predictive role was reported. This was similar to Matthew et al [18] and contradicts reports by [10] which confirmed its predictive role for histological grading only.

Based on IL-28B rs12979860 C/T polymorphism genotyping in patients who achieved SVR in the present study were similar to those reported in [19].

IL-28B rs12979860 C/T polymorphism appeared to predict the rate of response to pegylated IFN + RBV combined therapy in $\mathrm{CHC}$ patients. In the present study, the observed sharp decline in CC frequency among chronic HCV patients responding to pegylated IFN + RBV combined therapy vs. non responders $(29 \%$ vs. $6 \%)$ highlights the protective therapeutic role of IL28B $\mathrm{CC}$ in responding of chronic infection via INF immunomodulation. A comparable increase in the $\mathrm{T} / \mathrm{T}$ genotype was not observed in $\mathrm{CHC}$ patients indicating other factors are involved in viral persistence during progression to a chronic state. The current high frequency of $\mathrm{C} / \mathrm{C}$ in subjects with spontaneous clearance of the $\mathrm{HCV}$ is compatible with the protective role of the $\mathrm{C} / \mathrm{C}$ genotype against viral persistence.
Recently, Fabris et al [16] reported that in patients with chronic HCV infections, carriage of the $T / T$ genotype occurred more frequently in those patients affected by ESLD than in those with mild chronic hepatitis, thus supporting the results of the present study. The present data also supports important recent results demonstrating that IL-28B polymorphisms are linked to a better response to antiviral treatment in patients with HCV chronic hepatitis $[12,17,18]$ and to a higher probability of clearing the virus during the natural history of a chronic HCV infection [4]. In logical terms, C/C genotype seems to be under-represented among patients with ESLD since carriage of the rs $12979860 \mathrm{C} / \mathrm{C}$ genotype protects from against the development of chronic HCV infection as well as the unfavourable outcomes in chronic viral hepatitis $\mathrm{C}$ either directly or via its role in inhibiting HCV replication leading in most instances to spontaneous or IFN induced viral clearance during the early stages of infection. On the other hand, IL-28B rs12979860 C/T polymorphism the $\mathrm{T}$ allele appears to be more prevalent in patients with ESLD (LC and HCC).

Similar to earlier findings [16], the result of the univariate analysis of predictors of SVR showed that the baseline vitamin D serum level was an independent predictor of SVR. The predictive role of baseline serum vitamin $D$ on the attainment of SVR could be derived from the strong association found between vitamin $D$ and rapid virological response (RVR) attainment as reported previously [20]. However, this conflicts with the findings of Matthew et al [18] who showed that baseline vitamin $D$ level is not independently associated with SVR.

The exact mechanism of action of high vitamin $D$ level and the improvement of SVR is still debatable. Previous studies suggest that the immunomodulatory functions of vitamin $D$ contribute to increase viral response through its direct action on T-cell antigen-presenting cell function. More recently, Gutierrez and coworkers [21] showed that vitamin D3 increased vitamin D receptor (VDR) protein expression and inhibited viral replication in cell culture.

\section{Limitations of the study}

This study is a retrospective and therefore has some limitations such as selection bias, misclassification or information bias and the fact that some key statistics could not be done. Ethnic variation is one potential explanation for the differences observed between the findings obtained here and those reported by other researchers. 


\section{CONCLUSION}

The present study highlights the possible role for pretreatment serum vitamin $D$ level assessment in predicting the outcome of antiviral therapy in the treatment of naive patients with chronic hepatitis C. Furthermore, IL28B gene polymorphism, pretreatment HCV viral load and pretreatment vitamin $\mathrm{D}$ level can independently predict SVR in HCV 4a genotype.

\section{REFERENCES}

1. Hadziyannis SJ, Sette $H(J r)$, Morgan TR, Balan V, Diago $M$, Marcellin $P$, Ramadori $G$, Bodenheimer $H(J r)$, Bernstein D, et al. PEGASYS International Study Group Peginterferon-alpha2a and ribavirin combination therapy in chronic hepatitis $\mathrm{C}$ : a randomized study of treatment duration and ribavirin dose. Ann. Intern. Med. 2004; 140: 346-355.

2. Fried MW. Side effects of therapy of hepatitis $C$ and their management. Hepatology. 2002; 36: S237-S244.

3. Rauch A, Kutalik Z, Descombes P, Cai T, Di lulio J, Mueller $T$, Bochud M, Battegay $M$, Bernasconi $E$, Borovicka J, et al. Genetic variation in IL28B is associated with chronic hepatitis $C$ and treatment failure: a genome-wide association study. Gastroenterology. 2010; 138: 1338-1345.

4. Thompson AJ, Muir AJ, Sulkowski MS, Ge D, Fellay J, Shianna $K V$, Urban $T$, Afdhal $N H$, Jacobson $I M$, Esteban $R$ et al. Interleukin-28B polymorphism improves viral kinetics and is the strongest pretreatment predictor of sustained virologic response in genotype 1 hepatitis $C$ virus. Gastroenterology. 2010; 139: 120-129.

5. Bitetto $D$, Fattovich $G$, Fabris $C$, Ceriani E, Falleti $E$, Fornasiere E, Michela Pasino2, Donatella leluzzi2, Annarosa Cussigh1, Sara Cmet et al. Complementary role of vitamin $D$ deficiency and the interleukin-28B rs12979860 C/T polymorphism in predicting antiviral response in chronic hepatitis $C$. Hepatology. 2011; 53: 1118- 1126.

6. Deluca HF, Cantorna MT. Vitamin D: Its role and uses in immunology. FASEB J. 2001; 15: 2579- 2585.

7. Holick MF, Chen TC. Vitamin D deficiency: A worldwide problem with health consequences. Am. J. Clin. Nutr. 2008; 87: 1080S-1086S.

8. El Husseiny NM, Fahmy HM, Mohamed WA, Amin HH. Relationship between vitamin $D$ and IL-23, IL-17, and MCP-1 as markers of fibrosis in hepatitis $C$ Egyptians. World J. Hepatol. 2012; 4: 242-247.

9. Schaalan MF, Mohamed WA, Amin HH. Vitamin D deficiency: Correlation to IL-17, IL-23, and PIIINP in hepatitis C virus genotype 420. World J. Gastroenterol. 2012; 18: 3738- 3744

10. Abu Mouch S, Fireman Z, Jarchovsky J, Abdel-Rauf Z, Nimer A. Vitamin $D$ supplement improves sustained virologic response in chronic hepatitis $C$ (genotype 1)-naive patients. World J. Gastroenterol. 2011; 17: 5184-5190.

11. Lange C M, Bojunga J, Ramos-Lopez E, von Wagner M, Hassler A, Vermehren J, Herrmann E, Badenhoop K, Zeuzem S, Sarrazin C. Vitamin $D$ deficiency and a CYP27B1-1260 promoter polymorphism are associated with chronic hepatitis $C$ and poor response to IFNa-based therapy. J. Hepatol. 2011; 54: 887-893.

12. Kitson MT, Dore GJ, George J, Button P, McCaughan $G W$, Crawford $D H$, Sievert W, Weltman MD, Cheng WS, Roberts SK. Vitamin $D$ status does not predict sustained virologic response or fibrosis stage in chronic hepatitis $C$ genotype 1 infection. J Hepatol. 2013; 58(3): 467-472.

13. Bedossa P, Poynard T. An algorithm for the grading of activity in chronic hepatitis $C$. The METAVIR Cooperative Study Group. Hepatology. 1996; 24: 289-293.

14. El-Awady MK, Mostafa L, Tabll AA, Abdelhafez TH, Bader EI Din NG, Zayed N, Shenawy RE, El Abd Y, Hasan RM, Zaghlol $\mathrm{H}$, et al. Association of IL28B SNP With Progression of Egyptian HCV Genotype 4 Patients to End Stage Liver Disease. Hepat Mon. 2012; 12(4): 271-277.

15. Pawlotsky, JM. Molecular diagnosis of viral hepatitis. Gastroenterology 2002; 122: 1554-1568

16. Bitetto D, Fabris C, Fornasiere E, Pipan C, Fumolo E, Cussigh A, Bignulin S, Cmet S, Fontanini E, Falleti E, et al. Vitamin $D$ supplementation improves response to antiviral treatment for recurrent hepatitis C. Transpl Int 2011; 24: 43-50.

17. Davide B, Giovanna F, Carlo F, Elisa C, Edmondo F, Ezio F, Michela P, Donatella I, Annarosa C, Sara C, et al. Complementary Role of Vitamin D Deficiency and the Interleukin-28B rs12979860 C/T Polymorphism in Predicting Antiviral Response in Chronic Hepatitis C. Hepatology 2011; 53: 11181126.

18. Kitson MT, Dore GJ, George J, Button P, McCaughan GW, Darrell HG, Sievert CW, Weltman MD, Wendy $S$, et al. Vitamin $D$ status does not predict sustained virologic response or fibrosis stage in chronic hepatitis C genotype 1 infection. J Hepatol 2013; 59: 190-199.

19. Ge D, Fellay J, Thompson AJ, Simon JS, Shianna KV, Urban TJ, Heinzen EL, Qiu P, Bertelsen AH, Muir AJ, et al. Genetic variation in IL28B predicts hepatitis C treatment-induced viral clearance. Nature 2009; 461: 399-401.

20. Martinot-Peignoux M, Comanor L, Minor JM, Ripault MP, Pham BN, Boyer N, Castelnau C, Giuily N, Hendricks $D$, Marcellin $P$. Accurate model predicting sustained response at week 4 of therapy with pegylated interferon with ribavirin in patients with chronic hepatitis C. J Viral Hepat 2006; 13: 701-707.

21. Gal-Tanamy M, Bachmetov L, Ravid A, Koren R, Erman A, Tur-Kaspa R, Castelnau C, Giuily N, Hendricks D,

Trop J Pharm Res, October 2014; 13(10): 1731 
Abdelkader et al

Marcellin P. Vitamin D: an innate antiviral agent suppressing hepatitis $C$ virus in human hepatocytes.
Hepatology 2011; 54: 1570-1579. 